\title{
ULTRASOUND -GUIDED PECS II NERVE BLOCK IN A PATIENT WITH NEUROPATHIC CHEST WALL PAIN
}

M. Diakomi ${ }^{1}, \underline{\text { K. Vitoula }}{ }^{1}$, E. Nikolakopoulou ${ }^{1}$, A. Chrysikopoulou${ }^{1}$, E. Koutsopoulou ${ }^{1}$, Z. Gampopoulou1, M. Konstantinidou1.

${ }^{1}$ General Hospital of Attica "KAT", Pain Evaluation and Therapy Center, Athens, Greece.

\section{Background and Aims:}

Pectoralis nerve blocks are novel ultrasound-guided techniques that have been developed as alternative modalities to thoracic epidural, paravertebral and intercostal nerve blocks, for acute pain management following breast surgery. There is also information suggesting the possible role of pecs blocks in the management of chronic chest wall pain, but evidence is limited.

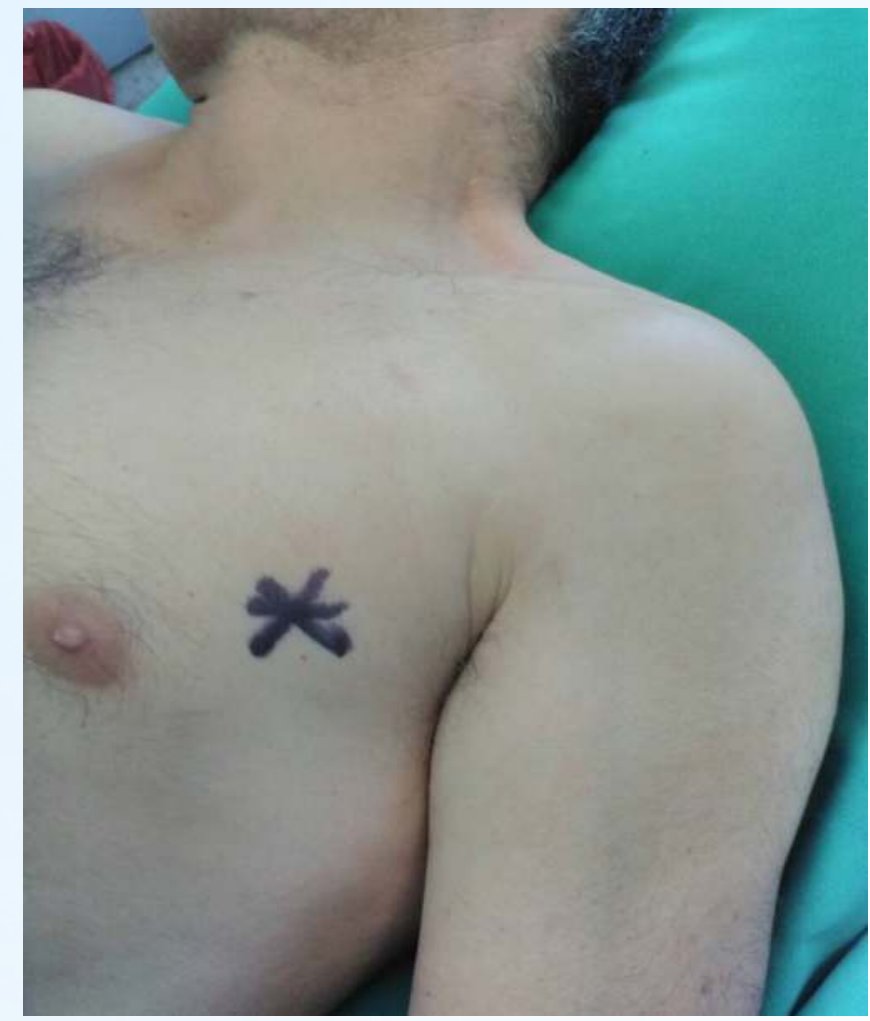

\section{Methods:}

A 40-year-old male underwent surgical brachial plexus investigation 14 years ago after he had been stubbed in the left trapezius muscle. He presented in our pain department 3 years ago with burning pain in the left shoulder zone and left upper arm. Interscalene nerve block was performed several times and treatment for neuropathic pain was prescribed. The examination of the patient two months ago revealed obvious trigger points on the left hemi thorax.
After explaining the procedure to the patient and having obtained informed consent, we performed ultrasound -guided pecs II block (20 $\mathrm{ml}$ ropivacaine $0,5 \%$ between pec minor and serratus anterior muscle and $10 \mathrm{ml}$ ropivacaine $0,5 \%$ between pec major and pec minor muscle / $8 \mathrm{mg}$ dexamethasone).

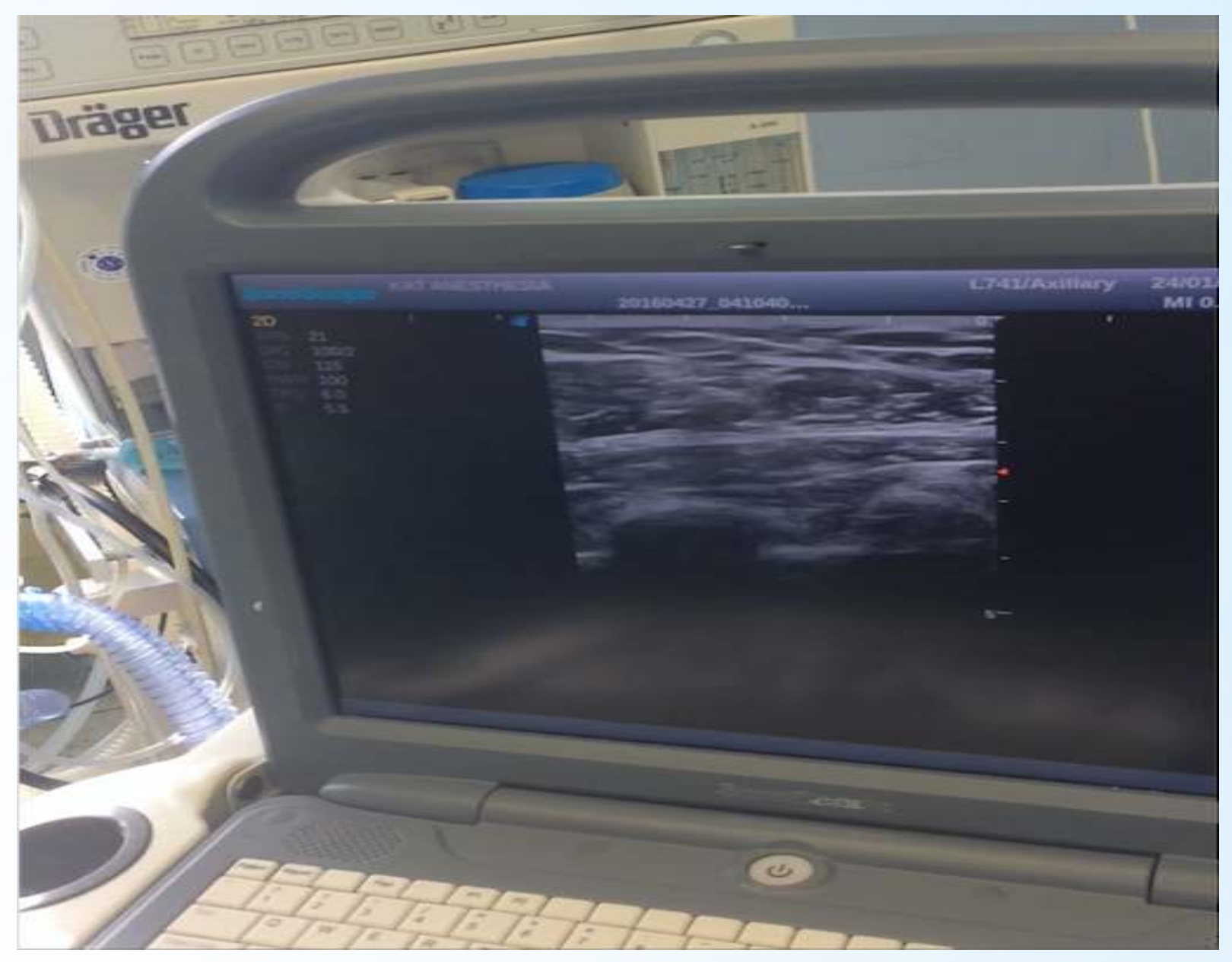

\section{Results}

The patient reported immediate pain relief after the procedure. The patient is on a weekly phone follow -up for already 60 days and reports to have near total chest wall pain relief.

\section{Conclusions:}

Our case provides possible evidence suggesting expanding the use of pectoralis nerve blocks from the field of acute to the field of chronic pain management.

1. Bashandy GM, Abbas DN. Pectoral nerves I and II blocks in multimodal analgesia for breast cancer surgery: a randomized clinical trial. Reg Anesth Pain Med. 2015 JanFeb; 40(1): 68-74.

2. Kurhade VS, Page ND.Pectoral nerve block. A novel modality for managing chronic chest wall pain. Indian J Pain 